\title{
Adiponectin and resistin: biomarker for colorectal cancer?
}

\author{
Viroj Wiwanitkit
}

Accepted: 25 March 2010/Published online: 15 April 2010

(C) Springer-Verlag 2010

\section{Dear Editor:}

I read the recent publication "Association between adiponectin, resistin, insulin resistance, and colorectal tumors" by Gonullu et al. (Int J Colorectal Dis. 2010; 25: 205-212) with great interest. Gonullu et al. concluded that "Adiponectin and resistin could play a role in colon cancer carcinogenesis, and adiponectin could be responsible for poor prognosis in colorectal cancer." Indeed, the use of adiponectin as a biomarker for colorectal marker is the presently focused issue. The report on this topic is still controversial. The difference in pattern of studies is the main concern. In the report of Gonullu et al., a problem of small number size might decrease the clinical usefulness of the result. In addition, it should be noted that the level of adiponectin can also be deviated by other possible concomitant disorders such as ovarian cystic disease. Also, the variants of adiponectin gene that result in different polymorphisms might have some effects on the pattern of adiponectin expression in colorectal cancer cases with different gene variants.

Conflict of interest No

V. Wiwanitkit $(\bowtie)$

Wiwanitkit House,

Bangkhae,

Bangkok 10160, Thailand

e-mail: wviroj@yahoo.com 